\title{
O COMPROMISSO DE ASSOCIAÇÕES DE MIGRANTES, ORGANIZAÇÕES E ACADEMIA PELOS DIREITOS HUMANOS DAS PESSOAS EM MOBILIDADE
}

\author{
Carmem Lussi*
}

\begin{abstract}
O texto desenvolve-se em três partes principais. Inicialmente apresentam-se algumas reflexões sobre as premissas que caracterizam a abordagem ao tema, em uma perspectiva "a partir de baixo". Seguem breves anotações sobre metodologias e objetivos do estudo e do compromisso pelos direitos humanos das pessoas e dos grupos em mobilidade e, enfim, apresentam-se elementos de análise de três tipologias de experiências de organizações de base sobre o tema da mobilidade humana, dos direitos de seus protagonistas e da busca por políticas migratórias norteadas por, ou pelo menos respeitosas dos direitos humanos das pessoas em mobilidade e suas famílias.
\end{abstract}

Palavras-chave: direitos humanos, migrantes, associações de migrantes, organizações da sociedade civil.

\section{Introdução}

Uma pergunta subjaz às reflexões que deram origem ao presente texto $^{1}$ : existem convergências ou possibilidades de articulação entre o compromisso das organizações ${ }^{2}$, grupos ou associações de base pelos direitos dos migrantes e o interesse do mundo acadêmico pelos mesmos atores?

\footnotetext{
* Consultora da Organização Internacional para as Migrações, OIM. Brasília - DF/Brasil.

${ }^{1} \mathrm{O}$ presente texto é uma versão ampliada de uma conferência apresentada na quinta sessão do Seminario Permanente sobre Migración Internacional: "Estrategias de incidencia social sobre políticas migratórias: perspectivas regionales en América Latina" do SEPMIG (México), realizado em Xalapa, em 04 de junho de 2010.

${ }^{2}$ No presente artigo utiliza-se "organizações de base" ou "organizações populares" como uma categoria sintética que inclui diversas formas de organização da sociedade civil, tais como movimentos sociais, ONGs, grupos pastorais, igrejas, associações, instituições culturais e filantrópicas e até as associações de migrantes. No decorrer do testo, ocasionalmente, são destacadas estas últimas por causa de sua especificidade a respeito do tema.
} 
Formulada nestes termos, a pergunta pode parecer óbvia, todavia esconde outras duas perguntas cujas respostas são difíceis de serem elaboradas, e que podem ser assim expressas:

- Que peso tiveram ou pretendem ter os esforços e as iniciativas das organizações militantes pelos $\mathrm{DDHH}$ dos migrantes na América Latina na formulação de políticas migratórias?

- Qual a incidência/relevância do trabalho acadêmico pela causa das pessoas e povos em mobilidade (pelos direitos humanos e respectivas políticas públicas) sobre os quais muitos pesquisadores estudam, escrevem, usam dinheiro público e até mesmo investem tempo, paixão e esforços?

O tema é altamente pertinente e as questões poderiam ser formuladas em uma série ampla de focos e nuances, mas nos limites deste texto serão sugeridos elementos de análise de alguns temas e processos considerados relevantes, do ponto de vista de quem aborda o tema, que está posicionada, de modo especial, a partir das organizações empenhadas pelos DDHH das pessoas em mobilidade, sem desdenhar a experiência e a preciosa contribuição das informações e das análises da academia.

\section{Sobre os migrantes, pelos migrantes e dos migrantes}

Diferentes perspectivas convivem como círculos concêntricos em um dinamismo espiral, nos meios e entre atores que pensam e atuam no contexto da mobilidade humana. Considera-se que o foco é na migração (e nas demais formas de mobilidade) e o centro desse dinamismo um simples ponto de partida, como uma alteridade que se apresenta e chama atenção, por consenso ou por dissenso em vários níveis.

O primeiro nível é "sobre os migrantes". Trata-se daquela etapa, que raramente desaparece, do interesse por um tema de moda ou de emergência contingente, que assume a forma de objeto de estudo para a academia. Nesta fase, para muitas das organizações militantes em tema de direitos humanos, os migrantes aparecem como vítimas em condição de vulnerabilidade a serem protegidas e defendidas. Nos discursos das organizações populares, este nível é o mais difuso e contemporaneamente o mais criticado, pela simples razão que a liberdade e a justiça exigem que todos os atores sejam parte ativa dos processos, das decisões e dos resultados que os interessam. Ao menos deveriam; migrantes também. Assim, a priori, também da academia espera-se que implique os e as "objetos de estudo" de modo a reconhecer-lhes, de fato, um protagonismo na qualidade dos produtos que as pesquisas e os estudos elaboram e divulgam. Nas organizações populares, o 
"sobre" se justifica pelas condições de vulnerabilidade em que se encontram os atores ou mesmo por uma declarada atitude de solidariedade por uma causa 'outra', que ainda não alcançou compromisso efetivo por parte dos principais atores. Este nível de compromisso leva à etapa seguinte, que chamamos de "pelos migrantes".

O segundo nível interpela diretamente a função social da universidade. Ou sua função política. Estudar para quê? Não é raro encontrar acadêmicos/ as que tomam posição e assumem posturas claras por determinadas causas sobre as quais estudaram, pesquisaram, escreveram. O "pelos migrantes" marcou a geração das décadas da grande militância do final do milênio passado, mas continua determinando estratégias de ação e discursos das organizações comprometidas pelos DDHH das pessoas em mobilidade e suas famílias. Na temática migratória a academia fala de governância dos fluxos migratórios, de formulação de políticas migratórias, de análise de dados, de argumentação para reformulação de leis, etc. com vistas a desenvolver uma função social da academia, que no contexto da mobilidade humana se configura como batalha pelos direitos e muitas vezes pela vida de quem migra. Apesar de certos contextos de base não terem uma longuíssima tradição de compromisso "pelos migrantes", esta causa já é uma bandeira assumida e tem no Fórum Social Mundial das Migrações, que nasceu na América Latina (em Porto Alegre, no sul do Brasil, em Janeiro de 2005), uma de suas expressões mais fortes. Este nível coloca a mobilidade humana entre os temas sociais na perspectiva de uma visão integral do compromisso pela promoção e defesa dos DDHH como direitos inalienáveis e indivisíveis que, portanto, se afirmam por si mesmos.

O terceiro nível é o "dos migrantes". Nas últimas décadas, fortaleceu-se uma convicção sempre mais forte nos contextos do empenho social, cultural e político em tema de DDHH, em geral, e de DDHH dos migrantes, em particular: o protagonismo das pessoas diretamente interessadas. Só a luta das pessoas que migram e suas famílias é que vai fazer a diferença. Neste nível a academia entra muito mais passivamente do que ativamente, apesar dos discursos sobre ética na metodologia de pesquisa sobre mobilidade humana, onde houve amplos questionementos sobre este aspecto. A academia tem o poder/dever - que vem do conhecimento, dos meios de divulgação aos quais tem acesso e dos recursos financeiros sobre os quais pode contar - de retro-alimentar as lutas pelos DDHH de migrantes, desplazados e refugiados. Pesquisadores e estudiosos podem dar voz, no sentido de fazer ecoar o que ouviram e recolheram e também de fomentar e multiplicar, através da interpretação (quando é pertinente), seja informações, 
que idéias e resultados que os migrantes mesmos lhe entregam nas pesquisas de campo. Só pouquíssimos migrantes são acadêmicos e a assunção da condição de mobilidade como um traço identitário e de interesse nem sempre se registra em tais fluxos. Portanto, o papel da academia na defesa e promoção do protagonismo dos migrantes não passa somente por uma eventual autobiográfica experiência migratória, mas pela qualidade da implicação dos atores estudados nos resultados e nos efeitos dos estudos realizados e divulgados. Neste nível estão as associações de migrantes. Muitas. Nem sempre bem articuladas. Com ciclos de vida por vezes breves, por vezes estagnados, por vezes parciais. Não faltam também experiências decididamente abrangentes e incisivas, como foi o caso do Equador, por exemplo, como explicam Ramirez Gallegos e Boccagni³

\section{a) Processos distintos. Metas comuns?}

Organizações de base e academia, teoricamente, se interessam pelas mesmas realidades de mobilidade humana. Em ambos os contextos, paradoxalmente, registram-se profissionais cegos às condições efetivas de vida e de futuro de quem vive os fluxos, por emigração, por ser left behind ou por movimento migratório de retorno. Em prática, as organizações populares lamentam uma parcialidade da academia, da qual esperam apoio e argumentos em favor de suas causas. A academia lamenta também pela parcialidade das organizações, por razões talvez mais contingentes que teóricas. Nos interrogamos sobre relações e, quem sabe, articulações e até mesmo recíproca implicação entre academia, organizações de engajamento sócio-cultural e pessoas/grupos em mobilidade, como um círculo virtuoso, que vai muito além do triângulo dos bons ou rebeldes (militantes), dos inteligentes (pesquisadores) e dos corajosos (migrantes).

Cabe salientar que, se nas organizações de base a manipulação ideológica pode arrastar coletivos inteiros para engajamento sem motivação refletida, com métodos e com envolvimento que não compreendem processos responsabilizantes e de adesão progressiva, também na academia registra-se empenho pela causa migratória por resultados encomendados, alienados ou até mesmo manipulados para finalidades comprometedoras, como, por exemplo, assessorias que levam a justificar decisões políticas em nível nacional e internacional por políticas de criminalização da imigração irregular, como tem acontecido, em certos países, nos últimos anos ${ }^{4}$.

\footnotetext{
${ }^{3}$ RAMIREZ GALLEGOS, Jacques; BOCCAGNI, Paolo. Voto a la distancia: análisis de la participación política de los ecuatorianos en el exterior.

${ }^{4}$ Cf. No caso da Espanha, ver GIL ARAúJO, Sandra. Las argucias de la integración. Políticas migratorias, construcción nacional u cuestión social.
} 
Segundo Bilger e Van Liempt, "a maioria das pesquisas no campo das migrações, e em particular no campo dos refugiados, tem suas origens em preocupações políticas [...]. Isto teria levado os pesquisadores a assumir as categorias, os conceitos e as prioridades dos policymakers ${ }^{\prime \prime}$, o que influencia as perguntas que determinam as pesquisas a serem realizadas, os temas de estudo a serem promovidos, as metodologias e até as análises adotadas. Todavia, cabe reconhecer que também nos contextos de sensibilização e militância popular, os temas e as lutas que catalizam energias, recursos e esforços nem sempre são ditados por prioridades avaliadas criticamente, e sim por escolhas de conveniência estratégica social e política.

A categoria "cidadania universal", usada já há anos como slogan sintético do ideal de luta dos movimentos sociais, tem encontrado aceitação também em certos contextos acadêmicos ${ }^{6}$, não tanto como convergência de estratégias, mas como indicação de consenso sobre uma visão utópica e de certo modo antagônica à perspectiva dos policymakers das últimas décadas, em tema de migrações.

\section{b) Visões e políticas}

$\mathrm{Na}$ perspectiva das organizações populares, o envolvimento na questão da mobilidade humana é um ato político. E, enquanto tal, nunca é neutro. A academia, em seu rigor científico, por vezes tenta tutelar-se da exposição que a tomada de posição política pode comportar; enquanto que movimentos, associações, igrejas empenhadas na causa migratória desafiam exatamente tal suposta neutralidade, porque o tema dos DDHH das pessoas em mobilidade inclui a vigilância sobre os abusos praticados em territórios 'outros', onde a neutralidade é conivência com a violação dos mesmos. Assim, por parte das organizações populares emerge, por vezes, uma espécie de radicalidade no compromisso e nas modalidades de atuação, que a academia não sabe nem poderia assumir, mas que não pode se eximir de influenciar, ou apoiando, ou enfraquecendo a luta com o desinteresse ou até mesmo o silêncio.

Pesquisar também é um ato político, se o tema e o contexto é a mobilidade humana, por mais que a academia possa tentar posicionar-se com neutralidade diante das abordagens do mundo político e governamental

\footnotetext{
${ }^{5}$ BILGER, Veronika; VAN LIEMPT, Ilse (eds.). The ethics of migration research methodology dealing with vulnerable immigrants, p. 2.

${ }^{6}$ CASTRO, Mary. Migrações internacionais e direitos humanos e o aporte do reconhecimento, $p$. 7-36. O volume n. 28 da REMHU publicou os atos do Seminário Migrações Internacionais e Direitos Humanos, realizado em Brasília em maio de 2008, ao qual participaram muitos estudiosos e militantes em direitos humanos das pessoas em mobilidade.
} 
ao tema. A questão é: quem se beneficia da ação empreendida? Seja ela de pesquisa ou ações de sensibilização e movimentação de base. O que conta é o peso simbólico e os resultados efetivos em termos de políticas, e até mesmo de serviços e de leis a introduzir ou fortalecer, assim como o papel de advocacy, para o qual o estudo é um fator determinante no êxito e na incidência do discurso. O debate sobre visões e políticas questiona a meta última do compromisso em contexto migratório, onde estejam envolvidos sujeitos em situação de vulnerabilidade ${ }^{7}$.

Outro fator importante a considerar é que "um amplo conjunto de fatores que podem estar ligados às migrações de modo periférico influencia as visões, percepções e ações dos migrantes" ${ }^{\prime 8}$, o que indica que tratar o tema das migrações isolando-o dos temas afins que compõem o tecido humano e sociocultural no qual quem migra vive, sonha e sofre, seria trabalho estéril em termos de resultados sociais e políticos.

O empowerment dos autores dos processos migratórios, independentemente da ação ou das estratégias com as quais organizações de migrantes, de base ou acadêmicas interagem com os referidos contextos, caracteriza um diferencial que qualifica a abordagem. Neste sentido, onde o empowerment é freado por formas de violência, discriminação ou outras formas de violação, para as organizações de base, a denuncia, articulada com campanhas de sensibilização, é o caminho que, obrigatoriamente, deve ser percorrido.

Para o Observatório de Políticas Públicas de Direitos Humanos, o foco do compromisso pelos DDHH das pessoas em mobilidade está em "abordar a questão centrando-se na pessoa e não [agindo] desde uma perspectiva do Estado e do mercado. Não obstante, mesmo o reconhecimento do direito a migrar supõe correlativamente a existência de um sujeito obrigado a facilitar e a garantir a realização desse direito, quer dizer, o próprio Estado" ${ }^{\prime \prime}$. Na perspectiva das organizações de base, engajadas neste campo, o compromisso é mais abrangente, ou pelo menos, quer ser. Implica que, além de centrar-se na pessoa, é também mantida a complexidade que sabe articular-se com todos os principais atores envolvidos, a comunidade e o contexto local, o momento histórico e político e o peso cultural que a mobilidade humana representa. Castro ${ }^{10}$ considera que os migrantes e as organizações que lutam

\footnotetext{
Sobre a concepção de vulnerabilidade aplicado a pessoas e grupos em mobilidade ver: LUSSI, Carmem; MARINUCCI, Roberto. Vulnerabilidade social em contexto migratório; LUSSI, Carmem. Conflitos e vulnerabilidades no processo migratório.

${ }^{8}$ BILGER, VAN LIEMPT, op. cit., p. 3.

${ }^{9}$ OBSERVATORIO DE POLITICAS PUBLICAS DE DERECHOS HUMANOS EN EL MERCOSUR. LaS migraciones humanas en el Mercosur. Una mirada desde los derechos humanos, p. 12.

${ }^{10}$ CASTRO, op. cit.
} 
pelos seus direitos reivindicam reconhecimento de sua dignidade e de seus direitos civis, políticos e sociais, buscando, em particular, o reconhecimento como cidadãos e cidadãs nos países de estada.

Quanto à capacidade de incidência neste tipo de processo, caberiam análises mais complexas, porque as denuncias de violações de DDHH e o desafio do empowerment das pessoas e grupos em mobilidade tem a ver com a ética no trabalho social, no serviço ou na pesquisa, que vai totalmente além dos limites deste texto.

\section{c) O kairós e o peso dos migrantes "de fora"}

A saída de pessoas e de inteiros fluxos da América Latina em direção às grandes potências econômicas - Europa, Japão e Estados Unidos juntamente com a evolução (ou involução) das políticas migratórias desses países trouxe, para dentro da América Latina, uma significativa experiência e uma força motora sem precedentes, que influenciaram em modo relevante, sobretudo em alguns países, a abordagem ao tema da emigração. Tal influência fomentou o compromisso, a partir da base, em prol de políticas públicas capazes de integrar as populações migrantes e emigrantes, suas necessidades próprias e sua contribuição para o desenvolvimento e para a transformação sociocultural do país de origem e daquele de destino.

No Brasil, por exemplo, o expressivo aumento de atenção do governo pelo tema da emigração no final da primeira década deste milênio deve-se muito à pressão que intelectuais brasileiros migrantes no exterior e, sobretudo, organizações sociais, culturais e eclesiais de emigrantes brasileiros no mundo, exercitaram sobre o governo brasileiro e sobre alguns órgãos, em particular. As reivindicações dos brasileiros e brasileiras no exterior levaram a migração para a agenda política, iniciando por uma forma muito parcial de atenção com o foco no trabalho, por um lado, e no tráfico de pessoas por outro, até levar a um compromisso público de interlocução do Ministério de Relações Exteriores que legitimou as "Comunidades de brasileiros e brasileiras no mundo" ao rango de interlocutoras do Governo Federal, com a realização de Conferências Internacionais em 2008, 2009 e 2010 ${ }^{11}$, além de muitas outras conquistas.

\section{Multiplicidade de abordagens: metodologias, metas e recursos}

O compromisso das organizações de base em geral, e das que atuam em contexto migratório em especial, muitas vezes não têm a continuidade que

\footnotetext{
${ }^{11}$ Cf. <http://www.brasileirosnomundo.mre.gov.br/pt-br>.
} 
a própria causa merece e que os discursos defendem. As lideranças, que têm papel determinante, nem sempre sabem ou conseguem desencadear processos autônomos e consolidados, fazendo com que metas importantes possam ser comprometidas em casos de indisponibilidade das pessoas específicas que os encabeçam. Outra causa desta dificuldade é que muitos processos indutivos no estabelecimento de estratégias de empenho podem até salvar o consenso sobre as metas, mas nem sempre garantem a efetiva convergência de esforços na mesma direção, que chegam a serem desperdiçados em tensões horizontais, ao invés de serem investidas de modo a somar conhecimentos, ganhos, experiências e astúcia em percursos mais incisivos. Recursos financeiros, na maioria das vezes recebidos por projetos ou, mais limitados ainda, por eventos, representam de fato um fator limitativo determinante no compromisso das organizações de base pelos DDHH das pessoas em mobilidade. As ambiguidades e os riscos a que se expõem tais organizações na dependência do dinheiro externo (público ou privado, nacional ou internacional) para a realização de suas atividades é desproporcional aos princípios e às estratégias promissoras desse tipo de trabalho. Estes são alguns exemplos de autocrítica "desde baixo". Sem entrar em mérito à adequada utilização de tais recursos, a dependência em si mesma de recursos impõe, por vezes, até mesmo o tipo de abordagem ao tema. Por vezes, quem financia decide o que vai apoiar; outras vezes o problema está no fato de que a necessidade de resultados visíveis leva a utilizar recursos para projetos pontuais, eventos grandes e atividades específicas, que por vezes não garantem a continuidade e consolidação de processos e a formação/valorização de lideranças que dinamizem organização, atividades e até mesmo motivação. Em contextos onde a encabeçar os processos são organizações menores, normalmente sem dinheiro e com recursos humanos voluntários, é mais provável a continuidade, porém a incidência em nível macro pode vir a faltar.

E na academia, qual autocrítica pode ajudar a pensar/analisar sua relação com as temáticas referentes aos DDHH das pessoas em mobilidade no que se refere ao poder de decisão sobre seu envolvimento e a qualidade do mesmo, à sua metodologia de abordagem e ao uso que faz dos recursos que tem, e que tem com muito maior continuidade (e quantidade?) que a organizações de base?

\section{Algumas tipologias de experiências interessantes na $A L$}

O questionamento inicial se transforma, nesta perspectiva, em uma questão não mais teórica ou estratégica, mas em um pressuposto. Não nos perguntamos tanto para saber, mas para saber como efetivar possibilidades 'outras' respeito às que presenciamos. Escolhendo como ângulo interpretativo 
o ponto de onde percebem e entendem o acesso aos direitos os sujeitos envolvidos nos processos migratórios, o discurso científico se faz análise mais antropológica e psicológica do que sociológica ou política. A pertinência de um espaço de interlocução sobre o tema dentro da academia é particularmente promissor enquanto é indicador de que, da academia pra fora, vem o sinal de uma capacidade de interação pluriforme e interdisciplinar, que não se acomoda na obtenção de um resultado final de pesquisa, mas é capaz de perguntar-se sobre o resultado que o uso de tal produto pode desencadear nos atores que o suscitaram, participando como objetos de estudo e, quem sabe, também como atores.

Para uma reflexão de amplo respiro, seguem alguns elementos de análise, destacando três macro grupos de organizações comprometidas com os DDHH das pessoas em mobilidade, por afinidade de estratégia utilizada, sem alguma pretensão de exaurir o tema, mas somente sugestão de análise. As três tipologias são, cada uma a seu modo, políticas ou ações de cunho político, e a apresentação é diferenciada somente para fins de reflexão, pois na prática convivem e necessitam uma das outras. O foco está na análise da relação entre envolvimento/ compromisso e formulação/adoção de políticas públicas correspondentes.

Fala-se de discursos e de ações diretas. Para as organizações de base e para a academia, no âmbito do compromisso pelos DDHH dos migrantes, desplazados e refugiados, discursos e ações correspondem a conceitos com valores semânticos absolutamente diferentes. A academia faz um discurso porque foi solicitada a pronunciar-se ou porque sabe que tem algo a dizer e sua fala é legítima, mesmo quando não é escutada. A militância não quer falar a, nem falar de, quer falar com; as organizações de base querem participar dos processos de tomada de decisão para influenciá-los diretamente, portanto querem participar da construção do discurso, na participação in itinere e não somente antes para assessorar, nem só depois para contestar. Tais organizações têm visões de metas e pretendem, nada menos, que ser parte nos processos que levam às decisões sobre a direção de tais metas, ou, ao menos, nos processos que decidem se tais metas serão de fato ou não adotadas politicamente. Qual a pretensão da academia na construção do discurso político? O discurso das organizações e, sobretudo, das associações de migrantes pede ações. Tal discurso tem um diferencial claro: é um discurso que se define como eco dos discursos teóricos e é formulado como feed back e em interlocução com os discursos políticos e, por vezes, aqueles acadêmicos. Na academia o discurso é um ato que se impõe por si mesmo, portanto, formalmente, o discurso acadêmico é uma ação, que a militância dificilmente consegue reconhecer em sua relevância. 
Cabe aqui una pergunta transversal: a academia está incluída quando as organizações de base se declaram sociedade civil? A questão aponta para una revisitação de alguns aspectos da relação aqui questionada. Apesar de não ser regra geral, registram-se casos em que a convergência de todos os atores no conceito de 'sociedade civil' é subentendida, como foi o caso dos participantes da III Jornada Hemisférica sobre Políticas Migratórias de 2009:

resulta imperativa a participação ativa e propositiva da sociedade civil para a construção coletiva de políticas públicas em matéria de migração e desenvolvimento. A participação efetiva da sociedade civil, o pleno alcance dos direitos e os enfoques diferencias, devem erigir-se em eixos centrais para articular os debates sobre segurança, direitos humanos (trabalhistas e de cidadania) e migrações... ${ }^{12}$

Seguem, em breve, as três tipologias que uma perspectiva fenomenológica evidencia no contexto da América Latina:

\section{a) As redes pelos migrantes}

Existem muitas. E já existiram muitas. Alguns exemplos: articulações políticas e acadêmicas em torno do tema da circulação de pessoas no marco da construção da Comunidade Andina de Nações e do Mercosul, com destaque especial ao papel desenvolvido pelo $\mathrm{CELADE}^{13}$; o papel da OIM ${ }^{14}$ e suas articulações, por exemplo, com os governos da América do Sul sobre temas específicos como o combate e a prevenção ao tráfico de pessoas; as articulações de inspiração religiosa como a rede feminina ${ }^{15}$ e a rede masculina de inspiração Scalabriniana ${ }^{16}$, a pastoral do migrante do CELAM $^{17}$, articulações de organizações pelos DDHH como a Plataforma Interamericana de Derechos Humanos, Democracía y Desarollo ${ }^{18}$ que desenvolveram no

\footnotetext{
12 Declaración Final de la III Jornada Hemisférica sobre Políticas Migratórias, 2009. Disponível em: <http://www.grupomigrantes.com/index.php?option=com_content\&task=view\&id=33>.

${ }^{13}$ Cf. $<$ http://www.eclac.org/celade $>$.

${ }^{14}$ Cf. $<$ http://www.oimconosur.org $>$.

15 Cf. <www.scalabriniane.org >. A rede feminina tem no Brasil seu Centro de Estudos sobre Migrações (cf. <www.csem.org.br>), onde publica a Revista REMHU, que semestralmente lança volumes temáticos sobre temas afins à mobilidade humana, com abordagem interdisciplinar. A rede masculina tem vários Centros de Estudos (dois na América Latina: Brasil e Argentina), entre o quais emerge, em nível de engajamento por melhores políticas migratórias internacionais, o CEMLA, de Buenos Aires (cf. <www.cemla.org $>$ ).

${ }^{16}$ Cf. $<$ www.scalabrini.net $>$ e $<$ www.scalabrini.org $>$.

${ }^{17}$ Consejo Episcopal Latinoamericano (cf. <www.celam.org $>$ ).

${ }^{18}$ A PIDHDD tem um GT Migrações, que articula e de certa forma representa uma parte significativa das articulações em rede sobre temáticas ligadas à mobilidade humana na América Latina. $<$ http://www.pidhdd.org > . O grupo migrações da Plataforma se articula no site <http://www. grupomigraciones.org $>$.
} 
decorrer do tempo uma atenção específica à populações em mobilidade ${ }^{19}$; assim como redes bem pontuais como o Grito dos Excluídos Continental ${ }^{20}$ e o Fórum Social Mundial das Migrações ${ }^{21}$. Um instrumento muito utilizado são os boletins, normalmente em formato eletrônico, como por exemplo, o Boletín AndinaMigrante ${ }^{22}$. Algumas das redes mais incisivas atualmente na temática migratória na América Latina - a Scalabrini International Migration Network e a Jesuit Migrant Service ou Jesuit Refugee Service - são ligadas a instituições católicas, mas atuam como ONGs e como tais se articulam, se organizam e intervém.

O GT migrações da Plataforma PIDHDD publicou, em 2007, um relatório sobre migrações ${ }^{23}$ que determinou um marco de referência sobre as possibilidades da articulação entre as muitas organizações, de diferentes perfis e com diferentes modalidades de intervenção, que haviam mostrado até então interesse e compromisso pela causa em contexto latino-americano e caribenho. Trata-se de um estudo sobre o tema: Migraciones y Derechos Humanos, editado no formato de um primeiro Informe da Consulta Permanente sobre Migraciones y Derechos Humanos en America Latina y el Caribe.

Outra rede importante no sentido de viabilizar políticas migratórias como estratégia para o alcance dos DDHH das pessoas em mobilidade é a AGP - Acción Global de los Pueblos sobre Migración, Desarrollo y Derechos Humanos ${ }^{24}$, nascido como resposta da sociedade civil organizada em ocasião do Foro Mundial sobre Migración y Desarrollo - FMMD, acontecido nas Filipinas, em outubro de 2008. A AGP tem, entre outros objetivos, o de incorporar a perspectiva dos DDHH no Forum Global citado ${ }^{25}$.

\footnotetext{
${ }^{19}$ Em 2008 chegou a constituir um Comitê de articulação em nível latinoamericano, que teve vida breve, mas revelou a força que o engajamento por direitos humanos e migrações tem conseguido entre as organizações comprometidas com os direitos humanos. Em 9 de abril de 2008, em ocasião da Segunda Reunião da Consulta sobre Migrações, a Plataforma publicou uma declaração, que reflete a visão a partir da qual abordam o tema organizações e academia, articuladas em contexto de fomento de políticas públicas. Cf. Declaración de Cuenca em <http:// www.grupomigrantes.com/index.php?option =com_jdownloads\&ltemid =50\&task=viewcategor $y \&$ catid $=8>$. Participaram do evento que produziu o a Declaração de Cuenca "60 delegados y delegadas de 45 asociaciones de migrantes, ONG de derechos humanos, Iglesias, académicos y organizaciones sociales de 13 países de la región".

${ }^{20}$ Cf. <http://www.gritodelosexcluidos.org>.

${ }^{21}$ O Fórum teve sua primeira edição em ocasião do Fórum Social Mundial de 2005, em Porto Alegre RS, Brasil e atualmente se realiza a cada dois anos. A segunda e a terceira edição, respectivamente em 2006 e 2008, foram em Rivas, na Espanha. Site : <http://www.fsmm2010.ec>.

${ }^{22}$ Cf. <http://flacsoandes.org/web/sima.html>.

${ }^{23}$ Texto completo em <http://www.grupomigrantes.com/index.php?option=com_jdownloads\&lte $\mathrm{mid}=50 \&$ task $=$ finish \&cid $=14 \&$ catid $=5>$.

${ }^{24}$ Cf. <http://www.mfasia.org/peoplesglobalaction>.

${ }^{25}$ Fabienne Venet Reciffé, diretora del INEDIM - Instituto de Estudios y Divulgación sobre la
} 
Algumas redes são específicas de áreas geográficas determinadas, como por exemplo, a Red Andina de Migraciones ${ }^{26}$ que articula organizações de Peru, Colômbia, Bolívia e Equador para fortalecer o papel da sociedade civil no processo de integração regional andino ou a Rede Andina Abriendo Mundos. Mujeres Migrantes, mujeres con derechos, que atua na mesma área geográfica ${ }^{27}$. Em nível regional pode-se citar também a Red Regional de las Organizaciones Civiles para las Migraciones - RROCM, a qual reúne 11 países da América Central e do Norte, e se propõe a "incidir na formulação, adoção e execução de políticas públicas, para contribuir, a partir de uma perspectiva integral, à proteção, defesa e promoção dos direitos humanos da população migrante, refugiada e seus familiares, nos lugares de origem, trânsito e destino" ${ }^{\prime 28}$. Interessante também é a experiência do grupo das Voces Mesoamericanas ${ }^{29}$ VM, que é um projeto em construção e multi-institucional da sociedade civil, cuja missão é aportar elementos para a construção de uma agenda social de migrações e desenvolvimento em nível regional de Norte e Mesoamérica.

Outras redes se estabelecem também em base ao tema ou à abordagem adotada, como foi, por exemplo, o Primer Encuentro de Defensoras y Defensores del Pueblo de la Región Andina y Centroamérica para la Protección y Promoción de los Derechos Humanos de las Personas en Movilidad y sus Familias, que elaborou, em 18 de setembro de 2009, o Acuerdo Defensoria ${ }^{30}$. No Mercosul, uma contribuição pontual e qualificada foi dada pelo Observatório de Políticas Públicas de Direitos Humanos no Mercosul, que se configura como representante da sociedade civil e de fato é composto fundamentalmente de acadêmicos e acadêmicas. Com financiamento Unesco, em 2009, publicou o Relatório Las migraciones humanas en el Mercosur. Una mirada desde los derechos humanos ${ }^{31}$ onde se ressalta o interesse em incorporar na agenda do Mercosul o tema dos direitos humanos dos migrantes.

\footnotetext{
Migración, membro da AGP, in Seminario Permanente sobre migración Internacional - Xalapa, Veracruz, 4 de junio de 2010, p. 22.

${ }^{26}$ Cf. <http://redandinademigraciones.org $>$.

${ }^{27}$ Cf. <http://abriendomundos.org $>$.

${ }^{28}$ Cf. <http://rrocm.com/mision.html>.

${ }^{29} \mathrm{Cf}$. < http://vocesmesoamericanas.blogspot.com > . O grupo Voces Mesoamericanas realizou uma missão em Washington em favor de uma política migratória e de desenvolvimento, em maio de 2010, cujo relatório oferece amplas pistas para a análise sobre as estratégias com as quais também a sociedade civil pode contribuir em tema de políticas migratórias.

${ }^{30} \mathrm{Cf}$. <http://www.grupomigrantes.com/index.php?option $=$ com_jdownloads\&ltemid $=50 \&$ task $=$ vi ewcategory\&catid $=8>$.

${ }^{31}$ O Observatorio de Políticas Públicas de Derechos Humanos en el MERCOSUR é formado por uma coalição de organizações da sociedade civil de Argentina, Brasil, Paraguai e Uruguai: < http://www. observatoriomercosur.org.uy/es/miembros.php>. OBSERVATORIO DE POLITICAS PUBLICAS DE DERECHOS HUMANOS EN EL MERCOSUR..., op. cit.
} 
Desde novembro de 2008 também o Espaço Sem Fronteiras se articula como rede que atua sobre temáticas migratórias, articulando movimentos sociais. Esta

é uma articulação sul-americana de organizações que trabalham com emigrantes, imigrantes, deslocados internos e refugiados, e organizações especializadas na promoção e defesa dos direitos humanos. Tem o objetivo fundamental de incidir politicamente nos espaços de tomada de decisão, principalmente na Conferência Sul-Americana de Migração - um encontro organizado pela da União das Nações SulAmericanas (UNASUL) para discutir política migratória. ${ }^{32}$

Crescem, também ao redor da causa migratória as formas de agregação que se articulam fundamentalmente através de redes sociais ou simples mailing list e se fortalecem em eventos, como aconteceu na Rio $+20^{33}$, no Rio de Janeiro, em 2012.

Para Neide Patarra ${ }^{34}$, o compromisso pelos DDHH dos migrantes é diretamente ligado com as políticas migratórias, porém "parece ser inevitável, no encaminhamento de propostas de governabilidade das migrações internacionais, tomar em conta a voz dos atores envolvidos - e essa voz, de maneira nítida e irreversível, se faz presente nos crescentes e fortes movimentos". Para a autora, as organizações de fato comprometidas pela causa nos termos de "pelos migrantes", são também espaços e canais para um efetivo "dar voz" a quem, de alguma maneira, está direta ou indiretamente implicado nos processos migratórios.

\section{b) As ações sem redes}

Também não faltam. Além das articulações entre migrantes, existem modalidades de compromisso pela causa das pessoas e povos em mobilidade que se destacam por sua estratégia com foco na incidência, mais do que na abrangência representativa da ação e das iniciativas a sustentar. Entre estas vale sublinhar, por um lado, as iniciativas promovidas ou realizadas por especialistas (pessoas ou instituições) em ocasião de eventos políticos dos governos da América Latina ou realizados na América Latina. Trata-se de intervenções pontuais, muitas vezes qualificadas, mas originadas e

\footnotetext{
${ }^{32}$ Cf. < http://www.cami-spm.org/not_09.html > e < http://www.espaciosinfronteras.org. Cf também Entre Tierras n. 7, dez 2008, in <www.acnur.org/biblioteca/pdf/6816.pdf $>$.

33 Uma das mailing list que atualmente estão articulando pessoas e grupos comprometidos com a causa migratória ao redor do mundo, e que é forte especialmente na América Latina usa o seguinte endereço email: <migrantes@forums.rio20.net>.

34 PATARRA, Neide Lopes. Migrações internacionais: teorias, políticas e movimentos sociais, p. 2122.
} 
desenvolvidas por especialistas, estrategicamente, sem claro nem efetivo envolvimento de grupos de defesa e promoção de direitos nem de grupos de migrantes, ao menos não de modo expressivo. Por outro lado, entre as intervenções que podem ser caracterizadas como isoladas ou não articuladas em redes, estão muitas iniciativas locais, nos respectivos países, onde a ação in loco desencadeia processos ou cria precedentes que sugerem ações em outros países ou junto com outros países, como foram diversos casos de regularização migratória bilateral, para a qual o papel de assessorias acadêmicas ou não - jogou importante papel.

No compromisso da academia por esse tipo de ação, existe uma força própria, pelo fato que em certos contextos os governos têm solicitado assessorias à academia, e esta, que pode realizar estudos a pedido, pode também incluir nos pedidos visões e chaves interpretativas dos dados, que podem abrir ou fechar portas à conquista de direitos. A América Latina tem exemplos de lutas que ganharam força pelo papel desempenhado pela academia, em especial sobre alguns temas, como os direitos dos indígenas. O que pode fazer a academia pelo reconhecimento de direitos das pessoas e povos em mobilidade é um campo aberto a infinitas possibilidades.

Um espaço privilegiado de encontro entre academia e organizações de base são os eventos de estudo, de partilha, de gestão de políticas e de discursos que gestam propostas políticas. Têm-se multiplicado por todo o continente. Por vezes dissimulam uma certa visão de que representam redes ou são sementeiras, mas normalmente não são redes efetivamente. São encontros de fios, mas que dificilmente se tornam ou se consolidam como redes, por razões mais contingentes que por razões políticas ou teóricas. Apesar de sua fragilidade como âmbito de articulação entre as duas instâncias, os eventos têm uma potencialidade expressiva pela força da sua polifuncionalidade para este tipo di trabalho transversal:

- fazem convergir todos os atores, que, uma vez reunidos, podem semear boas ideias e até desencadear processos interessantes;

- se afirmam em sua diferença e parcialidade, e esta revela-se uma necessidade para poder incidir;

- têm efeitos colaterais que marcam mais do que os resultados oficiais: aí fortalecem-se redes paralelas, exatamente nutrindo-se da interdisciplinaridade e interinstitucionalidade que os caracteriza.

Vale destacar que os eventos nutrem o discurso, que sustenta os líderes, que motiva os coletivos e abastece a mídia, que é a favor. O tema "a integração que queremos", que marcou a inserção do tema migratório nos processos Mercosul, foi uma dessas lutas populares que iniciou como tema 
transversal das redes pelos DDHH, depois entrou para as redes pelos DDHH de pessoas e grupos em mobilidade e penetrou discursos nos mais variados setores no sul da America do Sul e sugeriu temas políticos sobre a qualidade da integração que o Mercosul quer desenvolver de fato.

\section{c) As organizações de migrantes}

Uma das mais fortes expressões, simbolicamente, do compromisso dos migrantes mesmos pelos seus direitos aconteceu com o movimento em torno da Carta dos Migrantes ${ }^{35}$, uma iniciativa nascida na França ${ }^{36}$, mas que já nos primeiros passos teve no Chile um ponto de referência para a América Latina e que continua seu percurso, como evidenciado em junho de 2012, na Rio +20 . Trata-se de um projeto que nasceu em ocasião da ocupação de uma igreja, onde os migrantes mesmos decidiram tomar posição sobre sua realidade, considerando que existem nuances da realidade migratória que somente quem a vive sabe apresentá-la e caracterizá-la. Desta consciência decorre outra convicção que inspirou o movimento da Carta dos Migrantes: somente os migrantes têm a força de fato e a visão das metas pelas causas justas de sua jornada. O movimento pela Carta dos Migrantes nasceu querendo ser um espaço ou um meio de incidir politicamente em tema de migrações internacionais, e desenvolveu-se, não sem dificuldades.

Em alguns países, para temas pontuais como violência contra imigrantes no Paraguai ou anistia para imigrantes no Brasil, por exemplo, o peso das organizações de migrantes já foi determinante para o êxito de processos em políticas específicas ${ }^{37}$. Todavia, estudos sobre associativismo em emigração insistem sobre as dificuldades e a precariedade institucional das associações de migrantes, mais por razões antropológicas e sociais que por motivos teóricos ${ }^{38}$.

Por outro lado, Gonçalves considera que a falta de uma situação de regularidade de muitos imigrantes inibe e até impede sua atuação em prol

\footnotetext{
${ }^{35}$ Cf. < http://cmmigrants.org > . O movimento pela Carta dos Migrantes tem sido muito forte em seus primeiros passos, que podem ser acompanhados pelo referido site. Como muitas organizações de base, sofre suas fragilidades econômicas e estratégicas, nem sempre internas, mas também a causa dos contextos políticos nacionais e internacionais.

${ }^{36}$ Cf. <http://cmmigrants.org/spip.php?article2>.

${ }^{37}$ Cf. Terezinha Santin, diretora do CSEM - Centro Scalabriniano de Estudos Migratórios de Brasília. Entrevista à autora, de 20 de abril de 2010.

${ }^{38}$ Cf. LUSSI, Carmem. Entidades de união e de apoio a brasileiros e brasileiras no exterior. Seminário sobre Brasileiros no mundo, Rio de Janeiro, 17 e 18 de julho de 2008. Em <http://www. portalconsular.mre.gov.br/mundo/america-do-sul/republica-federativa-do-brasil/subsecretariageral-das-comunidades-brasileiras-no-exterior/informacoes/i-seminario-sobre-as-comunidadesbrasileiras-no-exterior\#temas $>$.
} 
de seus direitos em terra estrangeira, o que vem sendo registrado mesmo na América Latina, enquanto que a academia pode "abrir-se às realidades concretas daqueles que estão permanentemente a caminho; imigrantes e emigrantes, trabalhadores temporários, empregadas domésticas, vítimas do tráfico e da violência sexual e trabalhista... O encontro entre a pesquisa, os migrantes e as organizações que trabalham com eles tende a enriquecer as três partes" ${ }^{\prime \prime 39}$.

No Relatório da Comissão Global sobre as Migrações Internacionais de $2005^{40}$ as associações de migrantes são consideradas como importante grupo de pressão, mas não são reconhecidas como grupo de coesão e interlocutores políticos, de fato, o que, ao invés, é a perspectiva com a qual trabalham as organizações de base e pelas quais se dedicam, em tais associações, muitas pessoas comprometidas.

\section{Hipóteses de análise, sem conclusões}

O compromisso de organizações de base, associações de migrantes e academia pelo reconhecimento de direitos dos migrantes não é simplesmente o de defender, promover ou reforçar a noção de "direito a migrar como um direito humano". Vai muito além e se concretiza de maneiras distintas. A diferença, mais do que em metodologias e metas, está na origem: trata-se da research question ${ }^{41}$ na linguagem acadêmica ou da razão/motivação da luta, na maioria das demais organizações. Muitas são as metas, nem todas chegam ao compromisso efetivo pelos $\mathrm{DDHH}$, pois o discurso pode ser puramente ideológico ou publicitário. Engajamento e comprometimento é outra coisa.

Se, por um lado, as organizações que atuam pelos DDHH das pessoas e grupos em mobilidade podem chegar até a gerar modelos/propostas de políticas públicas, por outro lado, tais modelos e propostas não são adotados se as formas e canais onde o saber se sistematiza, circula e se configura como discurso político não entra em ação como capacidade de sinergia e incidência. Portanto, se para as organizações de base e as associações de migrantes - sobretudo para suas lideranças que nem sempre representam uma efetiva coletividade - o foco do "how to do it right" é fundamental, na academia esta pergunta é mais teórica do que efetiva, pois o compromisso pelos $\mathrm{DDHH}$ dos atores de uma pesquisa vai muito além dos códigos éticos de conduta ${ }^{42}$, que não podem abarcá-lo definitivamente. $\mathrm{O}$ fato que nem

\footnotetext{
${ }^{39}$ Alfredo Gonçalves, Superior Provincial dos Missionários Scalabrinianos de São Paulo. Entrevista à autora, de 25 de abril de 2010.

${ }^{40}$ Cf. <http://www.gcim.org/en/finalreport.html>.

${ }^{41}$ Cf. STARING, Richard. "Different methods to research irregular migration", p. 95.

${ }^{42}$ Cf. <www.respectproject.org $>$.
} 
todos os migrantes são pessoas ou grupos vulneráveis é uma das expressões desta específica complexidade que a mobilidade humana comporta, para qualquer tipo de abordagem que não ignore que vai estar em jogo, sempre, uma questão de direitos negados ou não reconhecidos, considerando-se a atual abordagem política internacional ao tema.

\section{Bibliografia essencial}

BILGER, Veronika; VAN LIEMPT, Ilse (eds.). The ethics of migration research methodology dealing with vulnerable immigrants. Brighton-Portland: Sussex Academic Press, 2009.

CASTRO, Mary. Migrações internacionais e direitos humanos e o aporte do reconhecimento. REMHU - Revista Interdisciplinar da Mobilidade Humana, v. 16, n. 28, 2008, p. 7-36.

DECLARACIÓN Final de la III Jornada Hemisférica sobre Políticas Migratórias, 2009. Disponível em: <http://www.grupomigrantes.com/index.php?option=com _ content\&task $=$ view\&id $=33>$.

GIL ARAÚJO, Sandra. Las argucias de la integración. Políticas migratorias, construcción nacional u cuestión social. Madrid: Lepala, 2010.

MIGRACIONES y Derechos Humanos. Informe da Consulta Permanente sobre Migraciones y Derechos Humanos en América Latina y el Caribe. Disponível em: $<$ http://www.grupomigrantes.com/index.php?option=com_jdownloads\&ltemid $=50 \&$ task $=$ finish \&cid $=14 \&$ catid $=5>$.

LUSSI, Carmem; MARINUCCI, Roberto. Vulnerabilidade social em contexto migratório. Disponível em: < http://www.csem.org.br/pdfs/vulnerabilidades_dos_ migrantes.pdf $>$.

LUSSI, Carmem. Conflitos e vulnerabilidades no processo migratório. Disponível em: <http://www.csem.org.br/2009/conflitos_e_vulnerabilidades_no_processo_ migratorio.pdf $>$.

PATARRA, Neide Lopes. Migrações internacionais: teorias, políticas e movimentos sociais. Estudos Avançados: Dossiê Migrações. São Paulo: USP, v. 2006, n. 57, 2006. . Principais fluxos migratórios entre os países da América do Sul, 2009. Disponível em: <https://sistema.planalto.gov.br/siseventos/migracoesAS/exec/ arquivos/ApresentacaoProfNeide.pdf $>$.

RAMIREZ GALLEGOS, Jacques; BOCCAGNI, Paolo. Voto a la distancia: análisis de la participación política de los ecuatorianos en el exterior. S/D. Disponível em: http://migrantologos.mx/articulos_maestros/Voto\%20Migrante\%20Ecuador.pdf. Acesso em 18.02.2011.

STARING, Richard. Different methods to research irregular migration. In BILGER, Veronika; VAN LIEMPT, Ilse (ed.). The ethics of migration research methodology dealing with vulnerable immigrants. Brighton-Portland; Sussex Academic Press, 2009. 


\section{Abstract}

The commitment of migrant associations, organizations, and the academy for human rights of people on the move

The text is developed in three main parts. Initially, a few reflections are made about the premises that characterize the approach to the topic in a perspective "starting from below". Following, are brief observations on the methodologies and objectives of the study and on the commitment with human rights of people and groups in mobility, and, finally, the article presents elements of analysis of three experience typologies of base organizations on the theme of human mobility, its protagonists' rights, and the search for migration policies directed by, or at least that respect, the human rights of people in mobility and of their families.

Keywords: human rights, migrants, migrant associations, civil society organizations.

Recebido para publicação em 20/07/2012.

Aceito para publicação em 24/09/2013.

Received for publication on July, 20 2012. Accepted for publication on September, 24 2013.

ISSN impresso: 1980-8585

ISSN eletrônico: 2237-9843 